\title{
Study of a complex water resources system with screening and simulation models
}

\author{
M C CHATURVEDI* and D K SRIVASTAVA $\dagger$ \\ * Applied Mechanics Department, Indian Institute of Technology, Hauzkhas, New Delhi \\ 110016 \\ † School of Hydrology, University of Roorkee, Roorkee 247667, India
}

\begin{abstract}
The study describes a sequential iterative modelling process for a complex water resource system. Two types of analytical models are used to find a reasonably small set of possible systems optimal design alternatives for a complex river basin. These models are a linear programming deterministic continuous (LPDC) model and a linear programing deterministic discontinous (LPDD) model. Linear programing has been used with linear approximation of the nonlinear functions. A simulation program has been developed which continues screening on the basis of the information obtained from the linear programing model. The models are developed in the context of analysis of the Narmada river, a large river basin in India, for which in the first instance alternative combinations and capacities of six major dams have to be decided.
\end{abstract}

Keywords. River basin planning; LP models; simulation techniques.

\section{Introduction}

Although considerable interest has developed of late in systems planning of water resources and it has been generally accepted that real-life applications are required to validate the efficacy and worthwhileness of certain techniques, studies of real-life complex systems are still relatively rare. For instance, it is well known that in view of the non-linearities and discontinuities in the objective function, the final analysis of a complex large real-life system could be best carried out by simulation. On the other hand, simulation over even a promising feasible set would be computationally impossible. Preliminary screening by a mathematical programming technique on the basis of which simulation could be planned has often been recommended (Dorfman 1962; Hufschmidt \& Fiering 1966; Roefs 1968; Roefs \& Bodin 1970; Loucks 1969). In this context, it is profitable to investigate the value of mathematical programming in preliminary screening and how it should be coupled with a simulation study. For instance it may be instructive to ascertain how deterministic linear programming models would help in identifying the optimal set in view of the stochastic inputs. An attempt was therefore made to study a real-life large scale complex system, the Narmada basin in India, by a combination of a mathematical programming screening model and a simulation model.

1. This paper has been reprinted with permission from the American Geophysical Union: Chaturvedi M C and Srivastava D K, Water Resources Res. 17: 783-796 (1981) C AGU

2. A list of symbols and indices is given at the end of the paper

3. Conversion table

1 inch $=2.54 \mathrm{~cm} ; 1$ foot $=0.3048 \mathrm{~m} ; 1$ mile $=1.609 \mathrm{~km} ; 1$ mile $=2.59 \mathrm{~km}^{2} ; 1$ acre $=0.405 \mathrm{ha} ; 1$ acre foot $=0.1234$ ha $\mathrm{m}, 1$ cusec $=0.02832$ cumec. 
In view of the large number of reservoirs being involved and the preliminary planning nature of the study a deterministic linear programming (LP) technique was adopted. However, two types of models-continuous and discontinuous-lirear programming deterministic (LPDC and LPDD) models were used following the suggestion of Loucks (1969). In continuous models the reservoir release always equals the difference between the water available (initial reservoir storage plus net inflow) in one period and the initial reservoir storage in the following period. But discontinuous models violate this continuity law for one or more periods, which may provide insights about excess storage and excess reservoir capacity needed for dry and wet years respectively. The simple deterministic programming models were used as preliminary screening models. A simulation technique was used for further analysis, to obtain a near optimum solution in terms of the objective function.

The approach was adopted independently of a similar approach to a combined screening-simulation study of a real-life large scale complex system by Jacoby $\&$ Loucks (1972). The results of the present study, carried out under different conditions, confirm and extend their findings.

\section{The problem}

The Narmada river basin ( 805 miles long and 50 miles wide) is located in Central India, within the state of Madhya Pradesh primarily, as shown in figure 1. The population density is 190 persons $/$ mile $^{2}$. The basin, with a potential of mean flows of about 28 million acre $\mathrm{ft}$ (MAF) at $75 \%$ availability and outstanding storage sites has undergone no development at all so far except for one dam recently constructed. There are 32

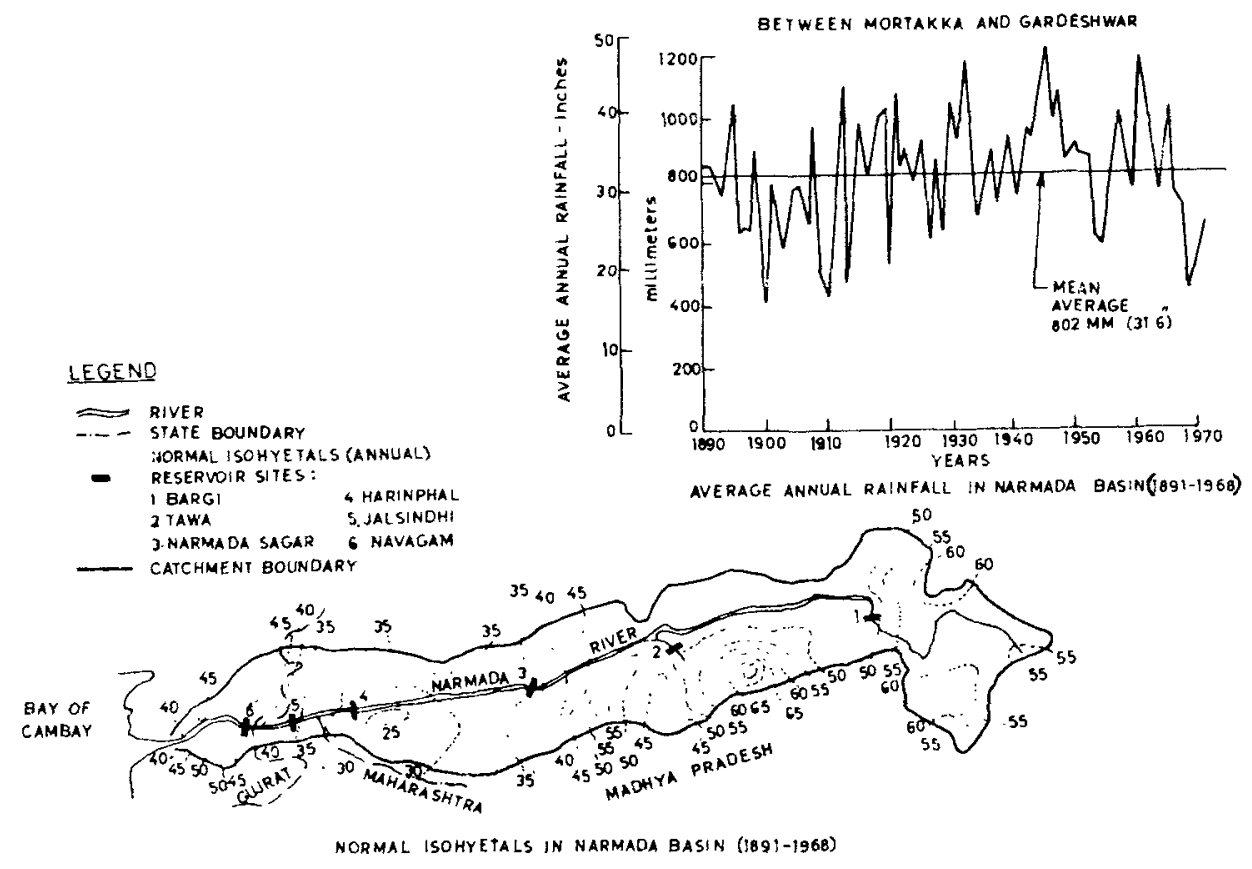

Figure 1. Hydrological characteristics of the Narmada system 
proposed reservoir sites, of which six are major ones. Thirty one lie in Madhya Pradesh and the last one, Navagam lies on the border of Madhya Pradesh and the downstream state of Gujarat. The sharing of waters between the two states and the proposed height of this dam are controversial. The yearly rainfall, and typical yearly rainfall pattern are shown in figure 1. The data have been collected from different reports (Master Plan 1972; Narmada Water Resources Development Committee 1965; and various Project Reports). The observed river flow data are over a period of 16 years.

In the first instance, alternative combinations, capacities and operating policies of six major dams-Bargi, Tawa, Narmadasagar, Harinphal, Jalsindhi and Navagam, as shown in figure 2 , are proposed to be investigated. There are three distinct alternatives listed in table 1 for this set of dams as three possible values for the height of the last dam, Navagam, have been chosen for analysis. In the first alternative shown in figure 2 , Navagam dam has the lowest height. In the second case, the height is raised till the first upstream dam, Jalsindhi, is submerged. In the third case the height is further increased till the next upstream dam, Harinphal, is also submerged. With increased water requirements at Navagam in the latter two cases, irrigation diversions of the upper dams would have to be modified. Two more alternatives, shown in table 1 are tried by replacing the single-purpose irrigation projects to single-purpose hydropower projects as suggested by some engineers. Multipurpose use has not been considered feasible for the first two dams.

The capacity, cost and net benefits at the various sites vary considerably because of hydrological and geological conditions. The average monthly flows based on a record of 16 years at the dam sites are shown in figure 3 . The reservoir capacity and capital costs are shown in figure 4 for illustration. For each of the alternatives the maximum permissible capacity is given from the physical configuration.

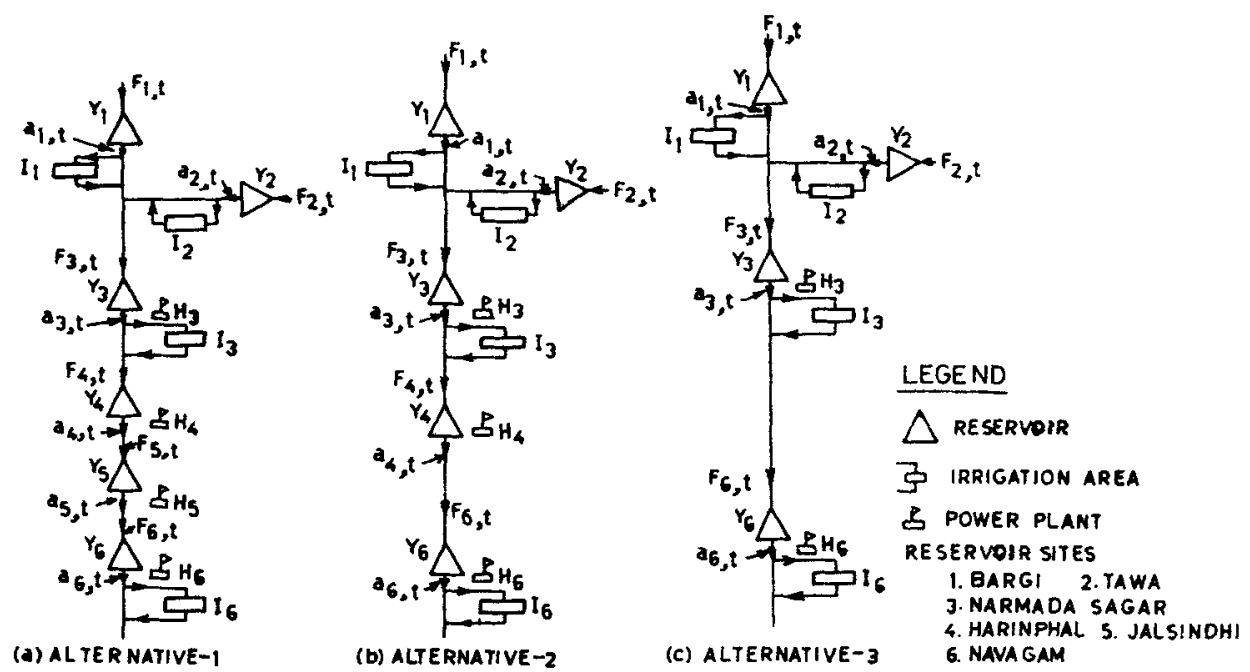

Figure 2. Alternative configurations of the Narmada system 
Table 1. Alternative configurations of the Narmada system

\begin{tabular}{|c|c|c|c|c|c|}
\hline \multicolumn{2}{|l|}{ Alternative 1} & \multicolumn{2}{|c|}{ Alternative 2} & \multicolumn{2}{|c|}{ Alternative 3} \\
\hline Project name & Purpose & Project name & Purpose & Project name & Purpose \\
\hline 1. Bargi & $I^{*}$ & 1. Bargi & I & 1. Bargi & I \\
\hline 2. Tawa & I & 2. Tawa & I & 2. Tawa & I \\
\hline 3. Narmadasagar & $I$ and $E^{* *}$ & 3. Narmadasagar & $I$ and $E$ & 3. Narmadasagar & $I$ and $E$ \\
\hline 4. Harinphal & $\mathbf{E}$ & 4. Harinphal & & 4. Navagam & $I$ and $E$ \\
\hline 5. Jalsinghi & $\mathbf{E}$ & 5. Navagam & $I$ and $E$ & & \\
\hline 6. Navagam & $I$ and $\mathbf{E}$ & & & & \\
\hline
\end{tabular}

\begin{tabular}{lllll} 
Alternative 4 & & & \multicolumn{2}{c}{ Alternative 5 } \\
\cline { 1 - 1 } Project name & Purpose & & Project name & Purpose \\
\hline 1. Bargi & $\mathrm{E}$ & & 1. Bargi & E \\
2. Tawa & I & & 2. Tawa & E \\
3. Narmadasagar & I and E & & 3. Narmadasagar & I and E \\
4. Harinphal & E & & 4. Navagam & I and E \\
5. Navagam & I and E & & \\
\hline
\end{tabular}

* I = irrigation; ** $\mathrm{E}=$ energy production

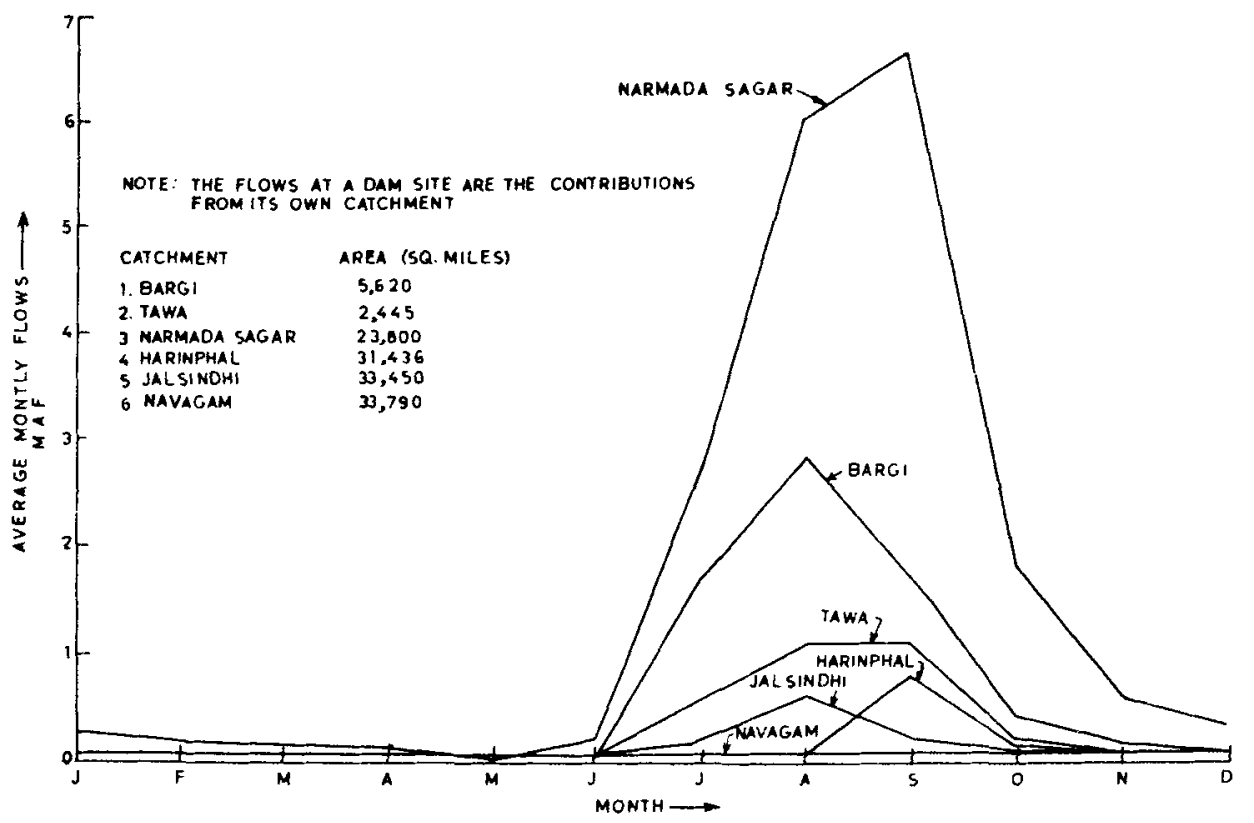

Figure 3. Average monthly flows at dam sites 


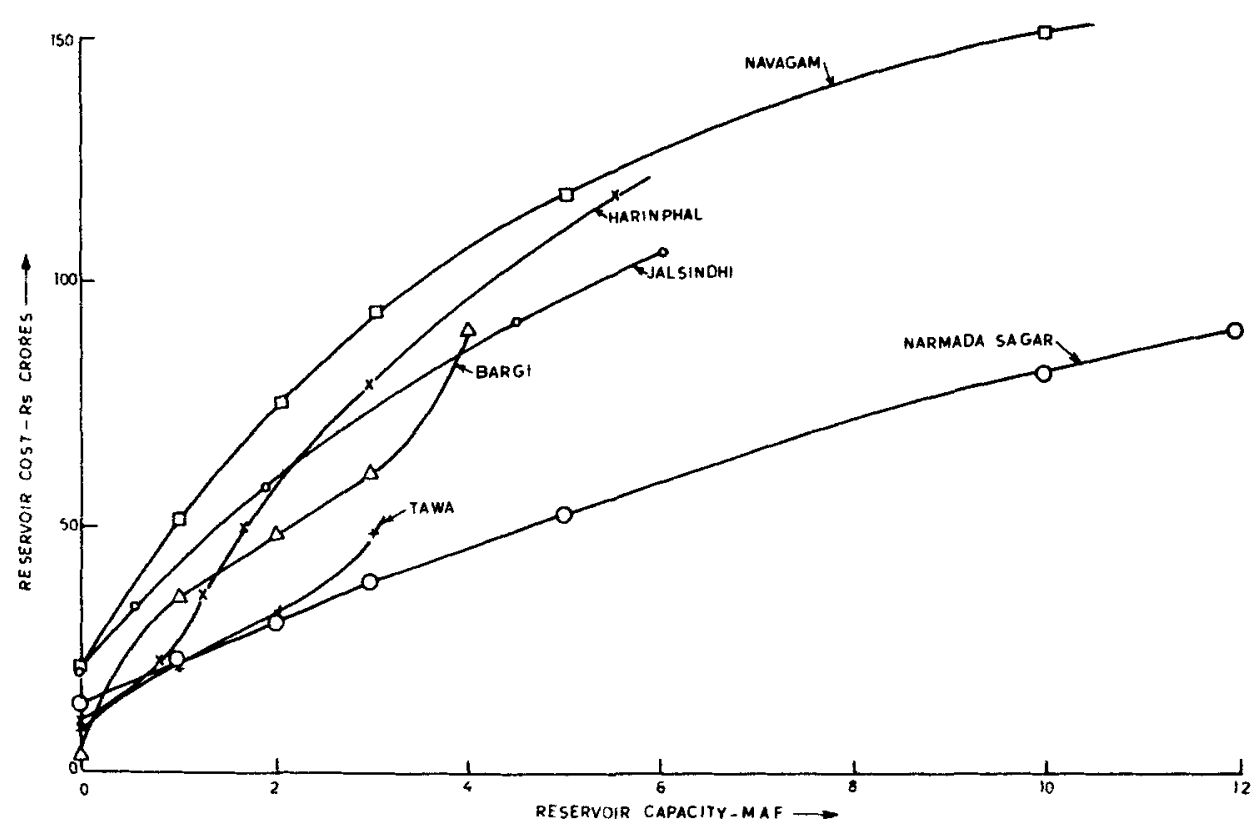

Figare 4. Reservoir capacity vs capital cost curves

\section{The models}

\subsection{Linear programing models}

The objective function is to maximize the total annual net benefits at all sites $i$.

$$
\text { Maximise: } \sum_{i}\left[B_{1, i}+B_{2, i}-\left(C_{1, i}+C_{2, i}+C_{3, i}\right)-\left(O_{1, i}+O_{2, i}+O_{3, i}\right)\right] \text {. }
$$

The first subscript 1,2 or 3 represents power, irrigation, or reservoir capacity respectively, and the second subscript $i$ represents a site in the system.

The maximization of the objective function is subject to the following constraints:

(a) The volume of water released from the reservoir must be sufficient to meet the irrigation demand in that period, i.e.

$$
a_{i, t}+f_{i, t} \geqslant K_{i, t} I_{i}, \quad \text { for all } i \text { and } t .
$$

(b) The volume of water released during any period cannot exceed the contents of the reservoir at the beginning plus the flow into the reservoir during the period, i.e.

$$
a_{i, t} \leqslant S_{i, t}+F_{i, t}, \quad \text { for all } i \text { and } t .
$$

$F_{i, t}$ is given by

$$
F_{i, t}=f_{i, t}+\sum_{j=1}^{z_{i}}\left(a_{j, t}+f_{j, t}^{\prime}-K_{j, t} I_{j}+K_{j, t}^{\prime} I_{j}\right), \quad \text { for all } i \text { and } t
$$


(c) The continuity equation for each reservoir site is defined as

$$
S_{i, t+1}=S_{i, t}+F_{i, t}-a_{i, t}, \text { for all } i \text { and } t \text {. }
$$

In the continuous (LPDC) model the reservoir contents at the end of the year, $S_{i, t+1}$, are assumed equal to the reservoir contents at the starting of the year $S_{i, 1}$, for all reservoir sites, but discontinuous (LPDD) models violated this continuity law for one or more periods.

(d) The contents of the reservoir at any period cannot exceed the capacity of the reservoir, or

$$
S_{i, t} \leqslant Y_{i}, \quad \text { for all } i \text { and } t .
$$

(e) The flow through the turbines should meet energy generation demand. Variation of generation efficiency at different sites is neglected at this stage

$$
\delta_{t} E_{i}-(1,025)(e)\left(\mathrm{He}_{i, t}\right)\left(a_{i, t}\right) \leqslant 0, \text { for all } i \text { and } t,
$$

where 1,025 converts million acre feet-feet to megawatt hours (MWh). At variable head sites, $\mathrm{He}_{i, t}$ is not a known constant. Therefore, together with $a_{i, t}$ it makes (6) a nonlinear one. Appropriate $\mathrm{He}_{i, t}$ was determined by trial and error as discussed later.

(f) Power production is also limited by the percent of time that the plant will produce power specified by the load factor

$$
\alpha_{i, t} h_{t}\left(H_{i}\right)-\delta_{t} E_{i} \geqslant 0, \quad \text { for all } i \text { and } t .
$$

\subsection{Simulation model}

A simulation program has been developed which continues the screening on the basis of iriformation obtained from the LP models given above. The rationale for adopting a particular operating procedure, i.e. a set of rules for storing and releasing water in reservoirs, is discussed later; it depends upon the alternative found most suitable for simulation.

\section{Computation}

In the first instance and also because of limited hydrologic data, historic hydrologic flows have been adopted for analysis. Hydrologic risk, evaporation losses, and flood control benefits were not included in these models, while seasonal flows were used. The LP model had 4 periods of equal length each year and the standard simplex program, the mathematical programing system (MPS) available with the IBM 360 Computer was used for solving the LP problem. The simulation model considered 12-monthly periods and the simulation program was developed on an International Computers Limited (ICL) 1909 computer.

The design values for cost and benefit were available for one capacity. These were therefore estimated for different possible ranges for each of the six projects on the basis of appropriate engineering approaches and suitable functions were developed (Srivastava 1976). On the basis of the project design and with the help of project authorities, sections for concrete dams (overflow and non-overflow section) and earth dams were developed and quantities and costs were worked out. The cost of auxiliary works was developed on a unit cost basis. The costs for the generating plant and 
equipment and auxiliary works were developed on a unit cost basis. The cost of irrigation and diversion works was also developed on a unit cost basis. Under these three major heads both direct and indirect charges were estimated for 1973 prices. Although they involved considerable work, it must be understood that the estimates are for a methodological study rather than for detailed design. The reservoir functions are given in figure 4. All capital costs were converted to annual costs for the linear programs. A time horizon of 16 years was used in the analysis and annual costs were calculated from the capital costs as the sum of the following items: (i) Interest on the capital cost of irrigation and power projects at $7 \%$ per annum; (2) depreciation on the capital cost of irrigation projects at $1 \% ;(3)$ annual depreciation and replacement of the power plant at $2 \%$ of the total cost of power plants; (4) maintenance cost of irrigation at Rs 6 per acre for the area to be irrigated; (5) annual cost of operation and maintenance for hydropower at Rs 10 per $\mathrm{kW}$ of installed capacity. In simulation the present value of net benefits extending over the period of study for the system was calculated.

\subsection{LP computations}

For both types of LP model, constraints were written only for one year. The decision variables were namely $a_{i, t} ; S_{i, t} ; Y_{i} ; H_{i}$ and $E_{i}$. LPDC models were the first type to be used and mean monthly flows were used as the input, as shown in table 2 . Values of $K_{i, i}$ and $\delta_{t}$ for each time period are given in table 3 .

Table 2. Mean flows at dam sites $\left(f_{i, t}\right)$

\begin{tabular}{lcccccc}
\hline \multirow{2}{*}{$\begin{array}{l}\text { Time } \\
\text { period }\end{array}$} & \multicolumn{5}{c}{ Mean flow* } & average taken for 16 years historic flow data (MAF) \\
\cline { 2 - 7 }$t$ & $\begin{array}{c}\text { Bargi } \\
i=1\end{array}$ & $\begin{array}{c}\text { Tawa } \\
i=2\end{array}$ & $\begin{array}{c}\text { Narmadasagar } \\
i=3\end{array}$ & $\begin{array}{c}\text { Harinphal } \\
i=4\end{array}$ & $\begin{array}{c}\text { Jalsindhi } \\
i=5\end{array}$ & $\begin{array}{c}\text { Navagam } \\
i=6\end{array}$ \\
\hline 1 & 0.08101 & 0.04118 & 0.54620 & 0.01405 & 0.03768 & 0.00288 \\
2 & $0-10043$ & 0.04232 & 0.37251 & 0.07613 & $0-02936$ & 0.00492 \\
3 & 6.23475 & 2.78181 & 15.29213 & 0.86832 & 1.26628 & 0.12533 \\
4 & 0.62159 & 0.29899 & 2.73611 & 0.19188 & 0.16823 & $0-02666$ \\
\hline Total & 7.03778 & 3.16430 & 18.94695 & 1.15038 & 1.50155 & 0.15979 \\
\hline
\end{tabular}

* The flows at a dam site are the contribution from its own catchment and are the sum of average monthly flows.

Table 3. Values of $K_{i, t}$ and $\delta_{t}$

\begin{tabular}{|c|c|c|c|c|c|}
\hline \multirow{2}{*}{$\begin{array}{l}\text { Time } \\
\text { period } \\
t\end{array}$} & \multicolumn{4}{|c|}{ Percentage of total annual irrigation requirement $K_{i, t}$} & \multirow{2}{*}{$\begin{array}{c}\text { Total } \\
\text { annual energy } \\
\text { requirement }{ }^{*}(\%) \\
t\end{array}$} \\
\hline & $\begin{array}{l}\text { Bargi } \\
i=1\end{array}$ & $\begin{array}{l}\text { Tawa } \\
i=2\end{array}$ & $\begin{array}{c}\text { Narmadasagar } \\
i=3\end{array}$ & $\begin{array}{c}\text { Navagam } \\
i=6\end{array}$ & \\
\hline 1 & 24.87 & $19 \cdot 49$ & $30 \cdot 52$ & $9 \cdot 39$ & 27 \\
\hline 2 & 21.73 & 5.55 & 32.01 & 28.07 & 21 \\
\hline 3 & 15.65 & $51 \cdot 12$ & 1106 & 30.93 & 24 \\
\hline 4 & $37 \cdot 75$ & 23.84 & $26 \cdot 41$ & $31 \cdot 61$ & 28 \\
\hline Total & 100.00 & $100 \cdot 00$ & $100 \cdot 00$ & 100.00 & 100 \\
\hline
\end{tabular}

* At $60 \%$ load factor 
Table 4. Values of cost and benefit functions

\begin{tabular}{lccccccc}
\hline $\mathrm{i}$ & $\beta_{2, i}$ & $C_{1, i}^{\prime}$ & $C_{2, i}^{\prime}$ & $C_{3, i}^{\prime}$ & $O_{1, i}^{\prime}$ & $O_{2, i}^{\prime}$ & $O_{3, i}^{\prime}$ \\
\hline \multicolumn{7}{c}{ All values are in Rs 10 million/unit item } \\
\hline 1 & $47 \cdot 70$ & 0.00574 & 1.870 & 1.560 & 0.001 & 0.2075 & - \\
2 & 22.45 & 0.00432 & 1.632 & - & 0.001 & 0.2345 & - \\
3 & 18.75 & 0.00504 & 3.370 & 0.640 & 0.001 & 0.1488 & - \\
4 & - & $\mathrm{a}^{*}$ & - & 1.377 & $\mathrm{~b}^{* *}$ & - & - \\
5 & - & $\mathrm{c}+$ & - & 1.400 & $\mathrm{~d} \ddagger$ & - & - \\
6 & 36.80 & 0.01500 & 3.105 & 1.272 & 0.001 & 0.2130 & - \\
\hline
\end{tabular}

* $H_{4}=H_{4,1}+H_{4,2}, H_{4,1} \leqslant 470, C_{1,4}=0.00641 H_{4,1}+0.00722 H_{4,2}$

** $D_{1,4}=0-001\left(H_{4,1}+H_{4,2}\right) ; \dagger H_{5}=H_{5,1}+H_{5,2}, H_{5,1} \leqslant 470$,

$O_{1,5}=0-00612 H_{5,1}+0-00791 H_{5,2} ; \ddagger O_{1.5}=0-001\left(H_{5,1}+H_{5,2}\right)$

$o_{3, i}^{\prime}=0$, in all cases.

The nonlinear objective function was made piecewise linear and the values of cost and benefit functions are shown in table 4 . In view of the preliminary nature of analysis for screening purposes, only linear functions approximating the concave or convex preliminary estimates were assumed or in hydropower plant cost functions, piecewise linearisation was assumed. The piecewise-linearised function is as follows:

$$
\begin{aligned}
\text { Maximize: } & \sum_{i}\left[\left\{\sum_{i}^{T} \delta_{i} \beta_{1, i, i} \sum_{s(i)} E_{i, s(i)}\right\}+\left\{\sum_{s(i)} b_{2, i, s(i)} I_{i, s(i)}\right\}\right. \\
- & \left\{\sum_{s(i)} l_{1, i, s(i)} H_{i, s(i)}+\sum_{s(i)} l_{2, i, s(i)} I_{i, s(i)}\right. \\
& \left.+\sum_{s(i)} l_{3, i, s(i)} Y_{i, s(i)}\right\}-\left\{\sum_{s(i)} m_{1, i, s(i)} H_{i, s(i)}\right. \\
& \left.\left.+\sum_{s(i)} m_{2, i, s(i)} I_{i, s(i)}+\sum_{s(i)} m_{3, i, s(i)} Y_{i, s(i)}\right\}\right]
\end{aligned}
$$

where, $E_{i, s(i)} ; H_{i, s(i)} ; I_{i, s(i)}$; and $Y_{i, s(i)}$ are portions $s(i)$ into which each target $i$ is divided, given by

$$
\begin{aligned}
E_{i} & =\sum_{s(i)} E_{i, s(i)}, & I_{i} & =\sum_{s(i)} I_{i, s(i)}, \\
H_{i} & =\sum_{s(i)} H_{i, s(i)}, & Y_{i} & =\sum_{s(i)} Y_{i, s(i)} .
\end{aligned}
$$

Similarly, the nonlinear constraint (6) was linearized by assuming an effective head and comparing it with the head specified in the model solution. Totally two runs were needed to match the effective head with the actual head. The gross reservoir capacity of the Tawa reservoir was taken as 1.874 MAF since it was already under construction in the system. The return flow $\left(K_{j, t}^{\prime}\right)$ was taken as $10 \%$ of the annual irrigation demand, as given in project reports. 
A few more constraints were added on the basis of some design criteria:

(i) In the Report of the Narmada Water Resources Development Committee (1965), it was recommended that sharing of water for irrigation between Madhya Pradesh and Gujarat should start when the total storage in all Madhya Pradesh reservoirs including Navagam reservoir is less than 16 MAF on 1 October. This fixes a lower limit of 16 as the total storage in all reservoirs on 1 October, i.e.,

$$
\sum_{i} S_{i, 4} \geqslant 16 \text {. }
$$

(ii) It is also recommended that the total irrigation water used by Madhya Pradesh should be at least 1.442 times that used by Gujarat in view of the greater area of the former, i.e.

$$
\sum_{i=1}^{5} I_{i} \geqslant 1.442 I_{6}
$$

(iii) The maximum irrigation water used by Gujarat should not exceed 10.65 MAF out of consideration of respective irrigable areas, i.e.

$$
I_{6} \leqslant 10 \cdot 65 \text {. }
$$

(iv) The total energy constraint fixed by the project authorities from consideration of hydropower component of total energy supply gave

$$
\sum_{i} E_{i} \geqslant 5,214,000, \text { for all } i \text {. }
$$

(v) The dead storage of a reservoir puts a lower limit on the reservoir storage in case of its producing power.

$$
S_{i, t} \geqslant D_{i}, \quad \text { for all } i \text { and } t .
$$

The values used were $D_{1}=0.6, D_{3}=2, D_{4}=0.342, D_{5}=0.15$, and $D_{6}=0.31$ all in MAF, as determined from usual engineering practice in design reports.

The results of the LPDC model when applied to various alternatives of table 1 are given in table 5 . The computational time taken by the largest problem containing 142 rows and 211 variables inclusive of slack variables was approximately 2 minutes. Results show that the maximum present value of net benefit of $R s 9,200$ crores is obtained for alternative 3 . The difference in the first three alternatives is not appreciable because the cost and contribution of the two replaced projects is comparatively small. Similarly, in schemes 4 and 5 replacement of irrigation by energy in projects 1 and 2 respectively is not economical. It is significant to note that benefits of energy go to project 1 at the cost of project 6 in scheme 4 while additional benefits accrue to project 3 in scheme 5 . Their results could not be anticipated by judgement as costs and benefits are not correlated in a simple transitive manner.

Alternative 3 identified as the optimal was chosen for analysis by the LPDD model. Dry years were defined using 0.95 and 0.75 of the mean flow, whereas only one wet year was considered using 1.25 of the mean flow. The results obtained are shown in table 6 as well as in figure 5 as percent of average flow figures for each item. Bounds were also included for the reservoir contents $S_{i, i}$ to avoid unbounded solutions, such that

$$
S_{i, t} \leqslant Y_{i}, \quad \text { for all } i \text { and } t .
$$


Table 5. Results of linear programing deterministic continuous (LPDC) model

\begin{tabular}{|c|c|c|c|c|c|}
\hline \multirow{2}{*}{ Variables* } & \multicolumn{5}{|c|}{ Alternative (refer table 1) } \\
\hline & 1 & 2 & 3 & 4 & 5 \\
\hline$Y_{1}$ & 5.133 & $5 \cdot 133$ & 5.133 & $4 \cdot 545$ & $0 \cdot 884$ \\
\hline$I_{1}$ & 7.037 & 7.037 & $7 \cdot 037$ & - & - \\
\hline$H_{1}$ & - & - & 一 & 121 & 38 \\
\hline$E_{1}$ & - & - & - & 944,273 & 297,857 \\
\hline$Y_{2}$ & 1.874 & 1.874 & 1.874 & 1.874 & 1.874 \\
\hline$I_{2}$ & 1.506 & 1.506 & $3 \cdot 164$ & $3 \cdot 164$ & - \\
\hline $\mathrm{H}_{2}$ & - & - & - & - & 23 \\
\hline$E_{2}$ & - & - & - & - & 181,074 \\
\hline$Y_{3}^{*}$ & 12.466 & 12.466 & 12.796 & $13 \cdot 598$ & 17.289 \\
\hline$I_{3}$ & $10-638$ & 10637 & 10957 & $20 \cdot 849$ & $19 \cdot 002$ \\
\hline $\mathrm{H}_{3}$ & 433 & 433 & 446 & 446 & 526 \\
\hline$E_{3}$ & $3,384,086$ & $3,384,086$ & $3,490,689$ & $3,643,199$ & $4,114,292$ \\
\hline$Y_{4}$ & 0.342 & 0.342 & - & $0-342$ & - \\
\hline $\mathrm{H}_{4}$ & 00 & 00 & - & $0-0$ & - \\
\hline$E_{4}$ & 00 & 0.0 & - & 00 & - \\
\hline$Y_{5}$ & 0.15 & - & - & - & - \\
\hline$H_{5}$ & $0-0$ & - & - & - & - \\
\hline$E_{5}$ & 00 & - & - & - & - \\
\hline$Y_{6}$ & $2 \cdot 882$ & 2.882 & 2.379 & 2.507 & 2.564 \\
\hline$I_{6}$ & 10.65 & 1065 & 10.65 & $10-65$ & $10-65$ \\
\hline$H_{6}$ & 234 & 234 & 220 & 80 & 159 \\
\hline$E_{6}$ & $1,829,914$ & $1,829,914$ & $1,723,321$ & 626,528 & $1,242,381$ \\
\hline$\Sigma E_{i}$ & $5,214,000$ & $5,214,000$ & $5,214,000$ & $5,214,000$ & $5,835,604$ \\
\hline$\Sigma I_{i}$ & 29.892 & 29.832 & 31.809 & 34.637 & 29.652 \\
\hline Benefit** & 8,9100 & $8,910 \cdot 0$ & $9,200-0$ & 7,5100 & 6,5500 \\
\hline $\begin{array}{l}\text { Benefits } \\
\text { as } \% \text { of ma }\end{array}$ & 96.7 & 96.7 & $100-0$ & 81.5 & 71.0 \\
\hline
\end{tabular}

- Y, gross reservoir capacities (MAF); $l$, annual irrigation targets (MAF); $H$, the hydropower capacities (MW); $E$, annual energy targets (MWh), subscripts 1 to 6 refer to the six sites.

** Benefits are present value of net annual benefits for 16 years in crores $\left(\times 10^{7}\right)$ of rupees.

It is seen from figure 5 and from table 6 , that for both dry and wet years the reservoir capacity of each reservoir was more than that needed for average flow. On the other hand, each irrigation target for dry years was less and for wet years it was more than what was required for average flow as was to be expected. However, the variation from one project to another is large, which could not be anticipated. Therefore, it can be said that the LPDD model estimates the complex variations required in capacities and targets during drought and wet years. It is then possible to fix ranges of design variables based on these results for simulation by random sampling as shown in table 7 .

\subsection{Simulation computations}

Simulation continued the screening on the basis of information obtained from $\mathrm{LP}$ models. The period of analysis of 16 years was chosen because of the availability of data. All the nonlinearities in the benefit-loss and cost functions were incorporated in the simulation model in an effort to keep the model real. The simulation model is static in 
Table 6. Results of linear programming deterministic discontinuous (LPDD) model (for alternative-3)

\begin{tabular}{|c|c|c|c|c|}
\hline \multirow[b]{2}{*}{ Variables } & \multicolumn{4}{|c|}{ Dry and wet years } \\
\hline & $\begin{array}{c}075 \text { Average } \\
\text { flow (dry) }\end{array}$ & $\begin{array}{c}0.95 \text { Average } \\
\text { flow (dry) }\end{array}$ & $\begin{array}{c}\text { Average } \\
\text { flowt }\end{array}$ & $\begin{array}{c}\text { 1.25 Average } \\
\text { flow (wet) }\end{array}$ \\
\hline$Y_{1}$ & 5.408 & $5 \cdot 188$ & $5 \cdot 133$ & 7.975 \\
\hline$I_{1}$ & $5 \cdot 278$ & 6.685 & 7.037 & $8 \cdot 797$ \\
\hline$Y_{2}$ & 1.874 & 1.874 & 1.874 & 1.874 \\
\hline$I_{2}$ & 0.000 & 3.006 & $3 \cdot 164$ & 3.769 \\
\hline$Y_{3}$ & 14.495 & 12.896 & 12.796 & 19.284 \\
\hline$I_{3}$ & 8.507 & 9.502 & 10957 & $19 \cdot 166$ \\
\hline $\mathrm{H}_{3}$ & 458 & 436 & 446 & 672 \\
\hline$E_{3}$ & $3,582,611$ & $3,407,902$ & $3,490,679$ & $5,252,965$ \\
\hline$Y_{6}$ & $4 \cdot 687$ & 2.551 & $2 \cdot 379$ & 3.994 \\
\hline$I_{6}$ & 9.560 & 10.650 & $10 \cdot 650$ & $10 \cdot 650$ \\
\hline $\mathrm{H}_{6}$ & 209 & 231 & 220 & 95 \\
\hline$E_{6}$ & $1,631,389$ & $1,806,098$ & $1,723,321$ & 741,137 \\
\hline$\Sigma E_{i}$ & $5,214,000$ & $5,214,000$ & $5,214,000$ & $5,994,102$ \\
\hline$\Sigma I_{i}$ & 23.345 & 29.843 & $31-808$ & $42 \cdot 382$ \\
\hline Benefits & 6,4600 & $8,280 \cdot 0$ & $9,200 \cdot 0$ & $9,350-0$ \\
\hline $\begin{array}{l}\text { Benefits } \\
\text { as percent } \\
\text { of average flow }\end{array}$ & 67.5 & 90.0 & 1000 & $101 \cdot 5$ \\
\hline
\end{tabular}

† Alternative 3 from table 5.

nature. The computer program for the Narmada simulation represents a considerable coding effort. It consists of a main routine, 26 subroutines and 9 function subprograms. Details are given in Srivastava (1976) and a simplified flow chart is given in figure 6.

For further screening with the help of a simulation model, alternative 3 of table 1 was found most suitable as was shown in the first part of the computation. Therefore the rationale of adopting a particular operating procedure for this alternative is derived below and discussed in detail by Srivastava (1976).

As far as possible, target outputs are met by unregulated flows in the system and by water that would otherwise spill or be released (basic release) from reservoirs to draw them down to flood-storage levels. Because energy deficits can be made up by purchase from outside the system or by thermal power plants, first preference is given to irrigation. Therefore, water is first drawn from reservoirs 1,2 and 3 to meet the target outputs for their respective irrigation areas. Water is released from reservoirs 1 and 2 by using the 'space rule' (Hufschmidt \& Fiering 1966) for combined releases, so that neither of them becomes empty nor remains full and to make the operating procedure variable, if the target for irrigation area 3 is not met. Water is drawn from reservoir 6 to meet the target output for irrigation area 6 . If the target output is not met the space rule is applied to reservoirs 1 and 2 . If the target is still not met water is released from reservoir 3. Energy is calculated from all the releases made upto now and if the energy target is not met water is drawn from reservoir 3 and then from 6 by using the 'compensating procedure' (Hufschmidt \& Fiering 1966). 


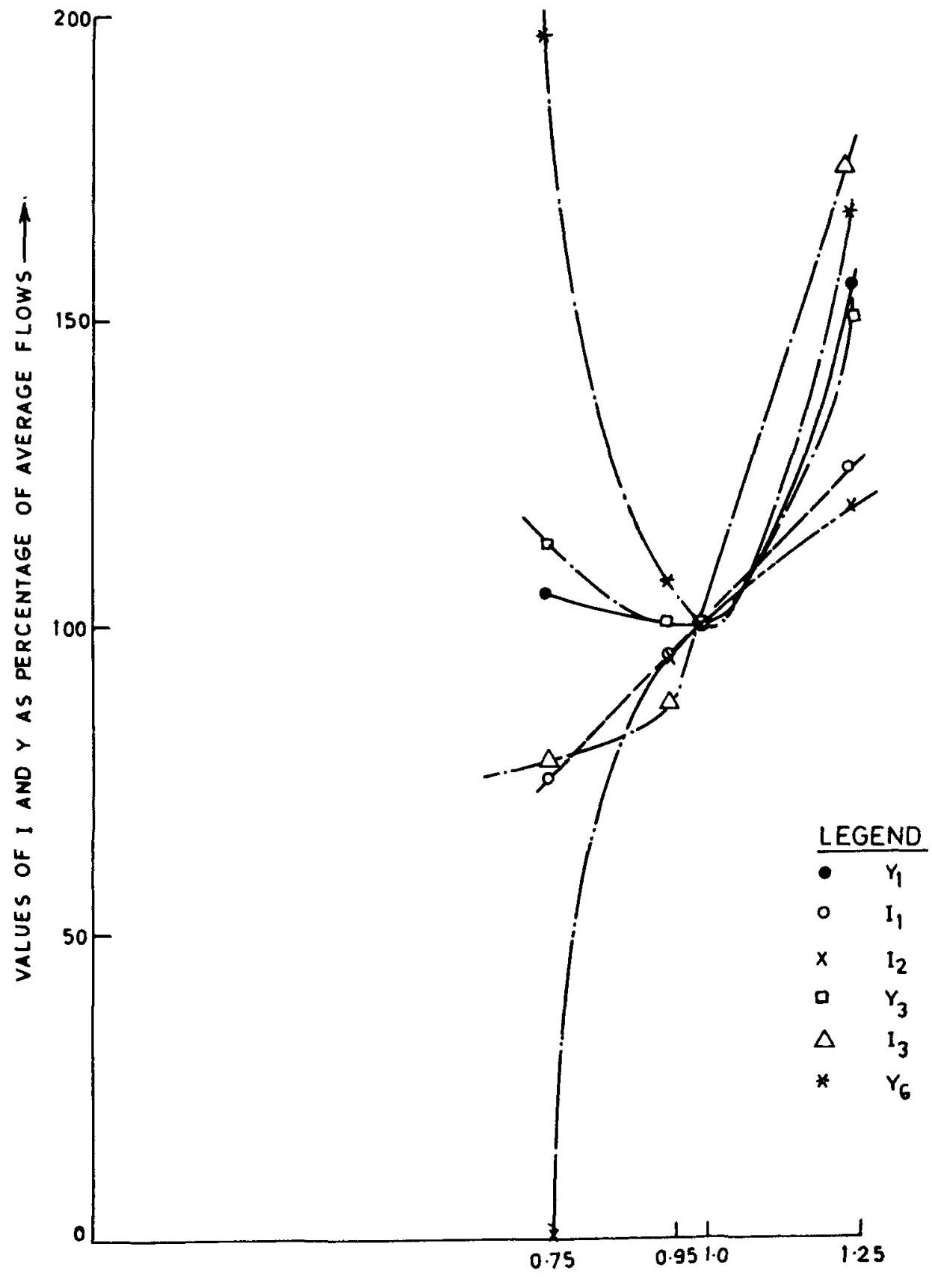

FLOWS AS PERCENTAGE OF AVERAGE FLOWS $\longrightarrow$

Figure 5. Variation of $I$ and $Y$ values for dry and wet years as percentage of average flows 

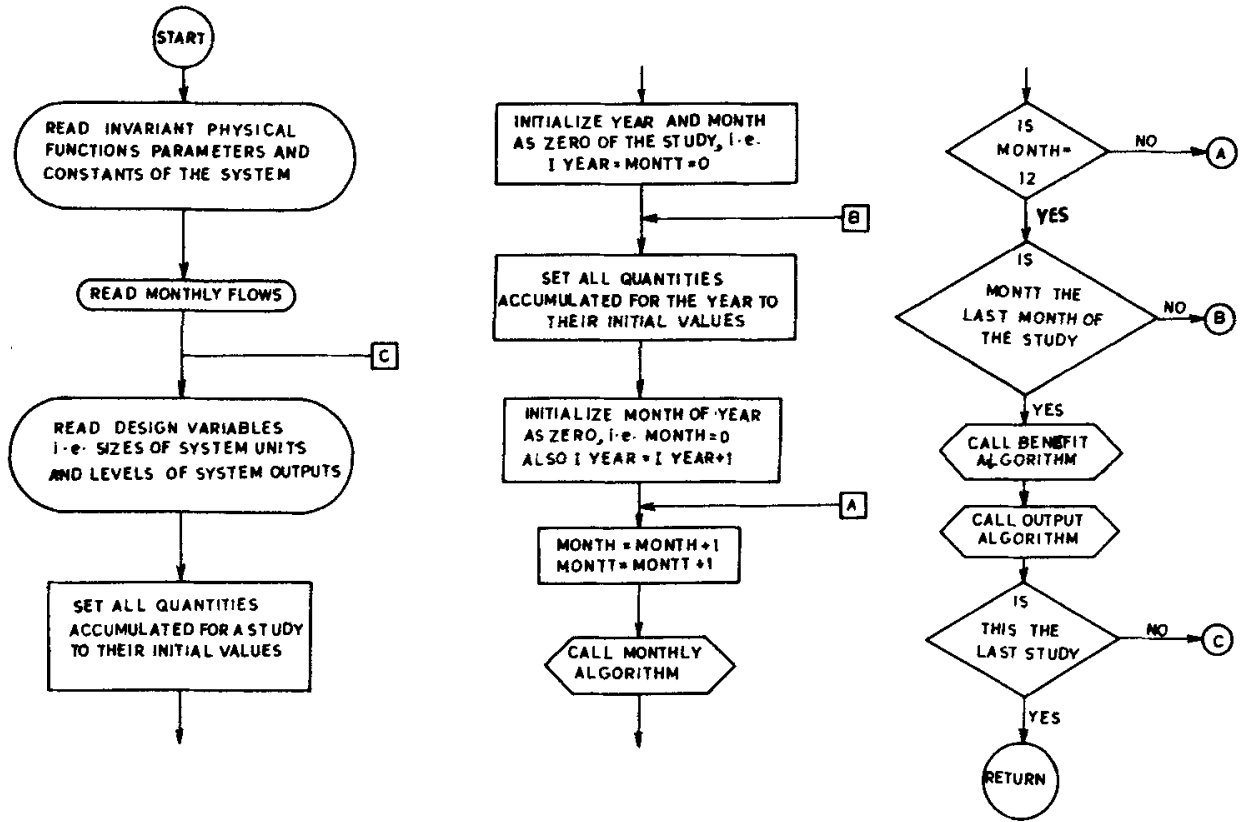

Figure 6. General flow chart of the Narmada simulation program

Table 7. Ranges and values of variables assigned for first random sample

\begin{tabular}{lrr}
\hline Variables & Ranges of variables & \multicolumn{2}{c}{$\begin{array}{c}\text { Values of variables assigned } \\
\text { for combination } 42^{*}\end{array}$} \\
\hline$Y_{1}$ & $4-9$ & $5 \cdot 746$ \\
$Y_{2}$ & $1 \cdot 874$ & $1 \cdot 874$ \\
$Y_{3}$ & $8-22$ & $19 \cdot 063$ \\
$D_{3}$ & $2-5$ & $3 \cdot 743$ \\
$Y_{6}$ & $2-6$ & $4 \cdot 471$ \\
$D_{6}$ & $0-31-2 \cdot 0$ & $0-760$ \\
$I_{1}$ & $3-9$ & $6 \cdot 070$ \\
$I_{2}$ & $0-4$ & $2 \cdot 338$ \\
$I_{3}$ & $6-20$ & $12 \cdot 547$ \\
$I_{6}$ & $9-10 \cdot 65$ & $10-635$ \\
$\Sigma E_{i}$ & $300-1,200$ & $3,437,100$ \\
$H_{3}$ & $50-800$ & 808 \\
$H_{6}$ & $0-2$ & 382 \\
$F S_{1}{ }^{\dagger}$ & $0-4$ & $0 \cdot 464$ \\
$F S_{3}$ & $0-1 \cdot 5$ & $2 \cdot 947$ \\
$F S_{6}$ & $2,000,000-5,214000$ & $1 \cdot 334$ \\
\hline
\end{tabular}

* This combination resulted in highest present value of net benefits of Rs 7,873 crores (i.e. $\times 10^{7}$ among the combinations simulated.

$\dagger F S i$ is the flood storage capacity in MAF for reservoir $i$. 
Table 8. Values of variables for combinations resulting in maximum present value of net benefits (in Rs crores) for different samples

\begin{tabular}{|c|c|c|c|c|}
\hline \multirow[b]{2}{*}{ Variables } & \multicolumn{4}{|c|}{ Types of samples } \\
\hline & $\begin{array}{l}\text { Second } \\
\text { random } \\
\text { sample }\end{array}$ & $\begin{array}{l}\text { Third } \\
\text { random } \\
\text { sample }\end{array}$ & $\begin{array}{l}\text { Fourth random } \\
\text { sample (from } \\
\text { LPDC model) }\end{array}$ & $\begin{array}{c}\text { LPDC } \\
\text { model } \\
\text { solution }\end{array}$ \\
\hline$Y_{1}$ & 6.559 & $6 \cdot 230$ & $4 \cdot 730$ & $5 \cdot 133$ \\
\hline$Y_{2}$ & 1.874 & 1.874 & 1.874 & 1.874 \\
\hline$Y_{3}$ & 20.656 & 17.633 & 11.072 & $12 \cdot 797$ \\
\hline$D_{3}$ & 3.401 & $2 \cdot 163$ & 2.082 & $2 \cdot 000$ \\
\hline$Y_{6}$ & $5 \cdot 150$ & $3 \cdot 186$ & 1.624 & $2 \cdot 380$ \\
\hline$D_{6}$ & $1 \cdot 205$ & $0-353$ & $0-343$ & 0.310 \\
\hline$I_{1}$ & $7 \cdot 383$ & 6.504 & $7 \cdot 181$ & 7.039 \\
\hline$I_{2}$ & 2.003 & 2.027 & $2 \cdot 541$ & $3 \cdot 164$ \\
\hline$I_{3}$ & $13 \cdot 279$ & $12 \cdot 105$ & $8 \cdot 647$ & $10-957$ \\
\hline$I_{6}$ & 9.836 & 10.616 & 10.605 & 10650 \\
\hline$\Sigma E_{i}$ & $2,383,961$ & $1,999,670$ & $1,999,670$ & $5,214,000$ \\
\hline $\mathrm{H}_{3}$ & 532 & 758 & 607 & 446 \\
\hline $\mathrm{H}_{6}$ & 164 & 266 & 214 & 220 \\
\hline$F S_{1} \dagger$ & 0.702 & 0.550 & $1 \cdot 114$ & 1.000 \\
\hline$F S_{3}$ & 2.445 & $2 \cdot 200$ & 1.920 & $2 \cdot 000$ \\
\hline$F S_{6}$ & 0.766 & 0.700 & 0.509 & 0.750 \\
\hline B十 & $7,998 \cdot 0$ & $7,914 \cdot 0$ & $7,468 \cdot 0$ & $7,830 \cdot 0$ \\
\hline
\end{tabular}

$\mathbf{D}=$ dead storage capacities

$+F S_{i}=$ flood storage capacity provided in MAF in reservoir $i$.

Simulation was carried out with the help of random sampling. Computational time for each simulation run was of the order of $\mathbf{4 0}$ seconds. In the first random sample ranges were selected for each variable as shown in table 7 , based on the results of the LPDD model from table 6. Fifty one combinations of 16 system variables were sampled at randon. These were reservoir capacities, dead storage capacities, irrigation requirements, energy requirements, hydropower plant capacities and flood constraints. This was done by assigning values to the variables in combinations through a computer program RANDOM, such that the allocations for flood and dead storages were not more than the gross reservoir capacity at each site individually or combined depending on the types of allocations to be made. The values of variables assigned in a first random sample to combination 42 which resulted in the highest present value of net benefits of Rs 7,873 crores are given in table 7 . Three more random samples were tried and their values of variables for combinations resulting in maximum present value of net benefits are given in table 8. Their present values of net benefits were Rs 7,998, Rs 7,914 and Rs 7,468 crores respectively. Similarly, the values of variables obtained by the LPDC model solution were also simulated. The present value of net benefits obtained was $\mathrm{Rs} 7,830$ crores.

\section{Analysis of results}

An LP screening technique was developed to determine the optimal configuration, capacities and multipurpose releases. It may, however, be noted that since linearization 
of concave cost functions is involved, there is a possibility of being trapped into local optimals. Looking at the results of the LPDC model in table 5, alternative 3 gave a maximum net annual benefit of Rs 9,200 crores. Results for other alternatives show that the capacities of reservoir Harinphal (no. 4) and Jalsindhi (no. 5) were restricted to their dead storage values in all the alternatives. This necessarily follows from the formulation adopted and to avoid this deficiency mixed integer programing would be required at subsequent more detailed analysis. The same holds for the power plants at these reservoirs. Hence, alternative 3 gives the probable optimal configuration of the physical facilities as well as their probable near optimal values.

If the results obtained in table 5 for alternative 3 and their corresponding values from the conventional design methods as shown in table 9 are compared the results from the LPDC model are reasonable and distinctly improved. The conventional design method is used here as the basis for comparison of the LPDC model results because it is the only one available as the system as such does not exist. This shows that the LPDC model is useful in choosing from the large number of alternative combinations of design, which would result in maximum net benefits.

Table 8 shows that the maximum present value of net benefits obtained in simulation for each case of random sampling and LPDC model simulation were nearly equal. On the other hand all combinations were efficient due to no excess reservoir capacity but inadmissible due to monthly irrigation and energy deficits (not shown in table 8 but for this refer to Srivastava 1976). The number of monthly deficits for irrigation in the LPDC model simulation was more than that obtained in the random sampling simulation, the reason being that the LPDC model specified higher annual output targets for irrigation. For energy the case was very much different: in most combinations the total energy deficits were large. This is because the relationship between the power plant capacity and the output is very complex and the LPDC model

Table 9. Comparison between LPDC and conventional design methods

\begin{tabular}{|c|c|c|c|c|c|c|}
\hline \multirow[b]{3}{*}{$\begin{array}{l}\text { Upto } \\
\text { No. }\end{array}$} & \multicolumn{4}{|c|}{ Reservoir capacity (MAF) } & \multicolumn{2}{|c|}{$\begin{array}{l}\text { Annual irrigation } \\
\text { requirement (MAF) }\end{array}$} \\
\hline & \multicolumn{2}{|c|}{ From report* } & \multicolumn{2}{|c|}{ From LPDC model** } & \multirow[b]{2}{*}{$\begin{array}{c}\text { From } \\
\text { report } \dagger\end{array}$} & \multirow[b]{2}{*}{$\begin{array}{c}\text { From LPDC } \\
\text { model** }\end{array}$} \\
\hline & $\begin{array}{c}\text { Gross } \\
\text { capa- } \\
\text { city }\end{array}$ & $\begin{array}{l}\text { Live } \\
\text { capa- } \\
\text { city }\end{array}$ & $\begin{array}{c}\text { Gross } \\
\text { capa- } \\
\text { city }\end{array}$ & $\begin{array}{c}\text { Live } \\
\text { Capa- } \\
\text { city }\end{array}$ & & \\
\hline 1. Bargi & $5 \cdot 548$ & $5 \cdot 548$ & $5 \cdot 133$ & $5 \cdot 133$ & 6.01 & $7 \cdot 037$ \\
\hline 2. Tawa & 1.874 & 1.874 & 1.874 & 1.874 & & $3 \cdot 164$ \\
\hline $\begin{array}{l}\text { 3. Narmada } \\
\text { sagar }\end{array}$ & 12.689 & $10-023$ & 12.796 & 10.796 & $14 \cdot 97 \dagger$ & 10.957 \\
\hline 4. Navagam & $4 \cdot 435$ & $2 \cdot 728$ & $2 \cdot 379$ & 2.069 & 11.02 & 10.650 \\
\hline Total & $24 \cdot 546$ & 20.173 & $22 \cdot 182$ & $19 \cdot 872$ & $32 \cdot 00$ & $31 \cdot 808$ \\
\hline
\end{tabular}

* Diagram 18.1, and Table 18.1, Vol. Ia (Master Plan for Development, 1972);

* Table 5 for Alternative 3;

+ Statement 18.1 Vol. II (Master Plan for Development of water resources of the Narmada in Madhya Pradesh, 1972);

+ Between Bargi and Narmadasagar. 
specified very low power plant capacities. Hence the values between power plant capacity specified by the LPDC model and that actually needed for simulation could vary. Even with the deviation between these results, it is seen that the LPDC model provided values of variables which were quite close to their corresponding values obtained by simulation.

\section{Conclusion}

For the systems analysis of a large complex water resources system a screeningsimulation model was developed. The Narmada river basin was taken as the system. Two types of LP screening models were used to find a reasonably small set of possible optimal design alternatives. These were LPDC and LPDD models. Simulation was used for further analysis to obtain the near optimum solution in terms of objective function.

The results showed firstly that the LPDC screening model gave realistic results as compared with those determined by the conventional design methods of project-byproject analysis. Second, the results of this model were helpful in simulation. Third, due to the introduction of some design and practical aspects as constraints in the LP model, the results obtained were more realistic and the solution was nearly optimal in terms of objective function. Fourth, this model specified output targets and capacities so as to better regulate mean monthly flows at all sites. Lastly, the LPDD model gave some idea of the excess storage and the reservoir capacity needed for drought and wet years respectively and helped in selecting the ranges of variables for simulation by random sampling for the alternative selected by the LPDC model.

The results of the simulation run from the LPDC model showed good resemblance of the design variables and results of simulation as did the results of simulation runs obtained by random sampling also. Within the limitations of the models, it may be concluded that the solution resulting from the LPDC model may be assumed to be near optimum in terms of objective function and can serve as an input or as an initial base for further screening by simulation.

\section{List of symbols}

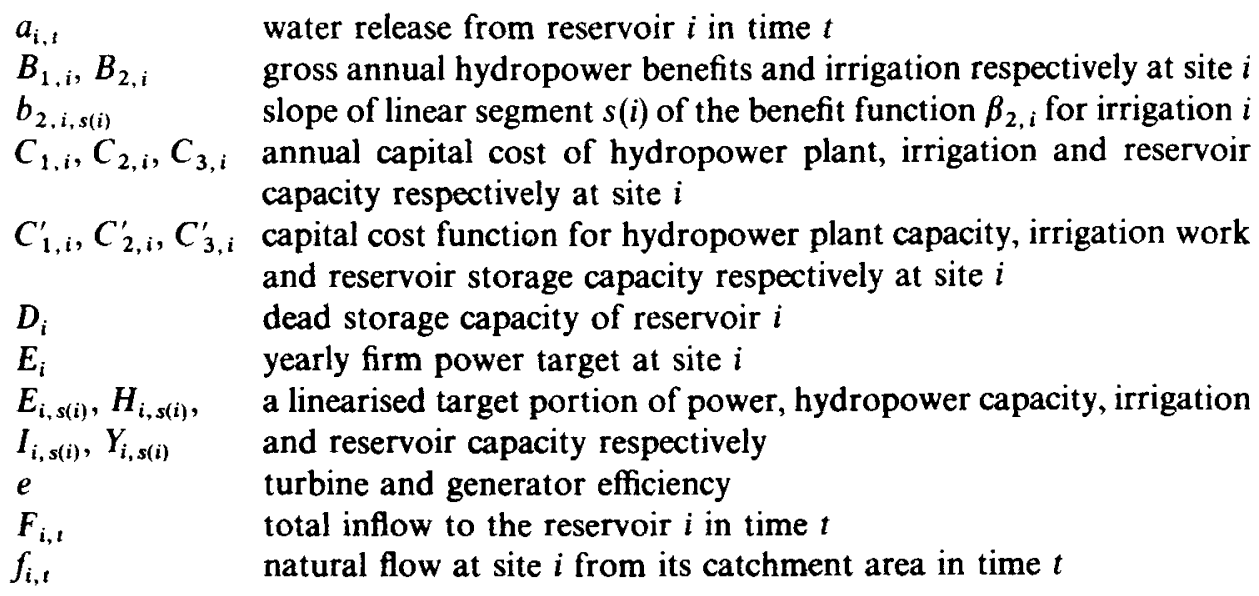




\begin{tabular}{|c|c|}
\hline $\mathrm{He}_{i, 2}$ & average storage head at site $i$ for period $t$ \\
\hline$h_{t}$ & r of hours in the particular period $t$ \\
\hline$H_{i}$ & hydropower capacity at site $i$ \\
\hline$I_{i}$ & $\begin{array}{l}\text { yearly target amount of water to be provided for irrigation for the } i \text { th } \\
\text { irrigation area }\end{array}$ \\
\hline$i$ & site, irrigation \\
\hline$K_{i, t}$ & $\begin{array}{l}\text { proportion of irrigation demand } I_{i} \text { to be diverted for irrigation in time } \\
t \text { from site } i\end{array}$ \\
\hline$K_{j, t}^{\prime}$ & $\begin{array}{l}\text { proportion of irrigation demand } I_{j} \text { as irrigation return flow from the } \\
j \text { th irrigation area in time } t\end{array}$ \\
\hline $\begin{array}{l}l_{1, i, s(i)}, l_{2, i, s(i)} \\
l_{3, i, s(i)}\end{array}$ & $\begin{array}{l}\text { slope of linear segment } s(i) \text { of the capital cost function for hydro- } \\
\text { power plant, irrigation work and reservoir storage capcity } \\
\text { respectively }\end{array}$ \\
\hline$m_{1, i, s(i)}, m_{2, i, s(i)}$, & slope of linear segment of the OMR cost function for hydropower \\
\hline$m_{3, i, s(i)}$ & plant, irrigation work and reservoir storage capacity respectively \\
\hline $\mathrm{O}_{1, i}, \mathrm{O}_{2, i}, \mathrm{O}_{3, i}$ & $\begin{array}{l}\text { annual omR cost of hydropower plant, irrigation work and reservoir } \\
\text { capacity respectively, at site } i\end{array}$ \\
\hline $\begin{array}{l}O_{1, i}^{\prime}, O_{2, i}^{\prime} \\
O_{3, i}^{\prime}\end{array}$ & $\begin{array}{l}\text { OMR cost function at site } i \text { for hydropower plant, irrigation work and } \\
\text { reservoir storage capacity resepctively }\end{array}$ \\
\hline$S_{i, t}$ & content of the reservoir $i$ at the beginning of period $t$ \\
\hline$s(i)$ & $\begin{array}{l}\text { number of portions into which target } i \text { is divided for linearization of } \\
\text { benefit and cost functions }\end{array}$ \\
\hline$t$ & time \\
\hline$Y_{i}$ & capacity of the $i$ th reservoir \\
\hline$Z_{i}$ & $\begin{array}{l}\text { set of reservoir sites upstream of site } i \text { from where water can reach the } \\
\text { site } i \text { (or the sites that contribute to the inflow at the site } i \text { ) }\end{array}$ \\
\hline$\alpha_{i, t}$ & $\begin{array}{l}\text { load factor at each hydropower site } i \text { and for each period } t \text { is an } \\
\text { indicator of the energy demand }\end{array}$ \\
\hline$\beta_{1}$ & benefit per unit of firm energy for site $i$ in time $t$ \\
\hline$\beta_{2, i}$ & the long run benefit function for irrigation at site $i$ \\
\hline$\delta_{t}$ & proportion of annual firm hydropower target $E_{i}$ for period $t$ \\
\hline
\end{tabular}

\section{References}

Dorfman R 1962 Mathematical models: the multi-structure approach design of water resources systems (Cambridge, Mass: Harvard University Press) p. 494

Hufschmidt M M, Fiering M B 1966 Simulation techniques for design of water resources systems (Cambridge, Mass: Harvard University Press)

Jacoby H D, Loucks D P 1972 Water Resources Res. 8: 1401

Loucks D P 1969 Stochastic methods for analysing river basin systems, Research Project Technical Completion Report, Department of Water Resources Engg. and the Water Resources and Marine Science Centre, Cornell Univ., Ithaca, New York

Master Plan for Development of Water Resources of the Narmada in Madhya Pradesh 1972, Government of Madhya Pradesh, Irrigation Department, Bhopal

Report of the Narmada Water Resources Development Committee 1965 Government of India, Ministry of Irrigation and Power, New Delhi

Roefs T G 1968 Reservoir management: the state-of-the-art, Report No. 320-350B, IBM, Washington Sci. Centre, Wheaton, Maryland, USA 
Roefs T G, Bodin L D 1970 Water Resources Res. 6: 410

Srivastava D K 1976 Optimisation of complex water resources systems by screening-simulation model, Ph.D. Thesis, Indian Institute of Technology, New Delhi

Various project reports: Project Reports of Bargi 1968; Tawa 1972; Narmadasagar 1969; Harinphal 1970; Jalsindhi 1970 and Navagam (Broach) 1956, available with Central Water and Power Commission, New Delhi 